Please do not remove this page

RMIT

UNIVERSITY

\title{
Anomalous first normal stress difference behavior of polymer nanocomposites and liquid crystalline polymer composites
}

Narimissa, Esmaeil; Rahman, Ahmed; Gupta, Rahul; Kao, Nhol; Bhattacharya, Satinath

https://researchrepository.rmit.edu.au/esploro/outputs/9921859169901341/filesAndLinks?institution=61RMIT_INST\&index=null

Narimissa, E., Rahman, A., Gupta, R., Kao, N., \& Bhattacharya, S. (2014). Anomalous first normal stress difference behavior of polymer nanocomposites and liquid crystalline polymer composites. Polymer Engineering and Science, 54(6), 1300-1312. https://doi.org/10.1002/pen.23675

Document Version: Submitted Version

Published Version: https://doi.org/10.1002/pen.23675

Repository homepage: https://researchrepository.rmit.edu.au

(c) 2013 Society of Plastics Engineers

Downloaded On 2023/04/26 21:27:02 +1000 
Thank you for downloading this document from the RMIT Research Repository.

The RMIT Research Repository is an open access database showcasing the research outputs of RMIT University researchers.

RMIT Research Repository: http://researchbank.rmit.edu.au/

\section{Citation:}

Narimissa, E, Rahman, A, Gupta, R, Kao, N and Bhattacharya, S 2013, '(In Press)

Anomalous first normal stress difference behavior of polymer nanocomposites and liquid crystalline polymer composites', Polymer Engineering and Science.

See this record in the RMIT Research Repository at:

http://researchbank.rmit.edu.au/view/rmit:21867

Version: Submitted Version

Copyright Statement: (c) 2013 Society of Plastics Engineers

Link to Published Version:

http://dx.doi.org/10.1002/pen.23675 


\title{
Anomalous First Normal Stress Difference Behaviour of Polymer Nanocomposites and Liquid Crystalline Polymer Composites
}

\author{
Esmaeil Narimissa, Ahmed Rahman, Rahul K.Gupta", Nhol Kao and Sati N. Bhattacharya \\ Rheology and Materials Processing (RMPC) Centre, School of Civil, Environmental and \\ Chemical Engineering, RMIT University, Melbourne, VIC, Australia \\ *Corresponding author's E-mail: rahul.gupta@rmit.edu.au
}

The first normal stress difference $\left(\mathrm{N}_{1}\right)$ behaviour of polymer nano-composites and liquid crystalline polymer (LCP) composites is a measure of elasticity and is affected by shear stress as a result of morphological alterations at the molecular and nanostructure levels. In this study, the steady shear rheological behaviours of polylactide (PLA) and nano-graphite platelet (NGP) bio-nano-composites containing 1, 2, 3, and $5 \mathrm{wt} \%$ nano-filler were investigated. The shear rheological properties of glass fibre-filled LCPs (filler aspect ratio $>$ 100) were also examined. One of the objectives of this study was to obtain a correlation between $\mathrm{N}_{1}$, filler contents, and shear stress/rate of the measurements. The results suggest that $\mathrm{N}_{1}$ in PLA/NGP bio-nano-composites is dependent on the level of filler loading as well as the shear rate beyond a critical value. For the LCP systems, $\mathrm{N}_{1}$ is positive for the unfilled and negative for the glass fibre-filled LCPs, respectively. A novel rectangular hyperbola model was successfully developed and utilized to fit the $\mathrm{N}_{1}$ data of the neat PLA and PLA/NGP composites as well as the unfilled LCPs. The anomalous $\mathrm{N}_{1}$ behaviour of PLA/NGP and LCP composites was also thoroughly discussed in this study.

Keywords: Shear rheology, Nanocomposites, Biodegradable Polymers, Liquid Crystalline Polymers (LCP), Composites 


\section{Introduction}

The shearing of viscoelastic materials between two parallel surfaces at a considerable shear rate results into the formation of viscous shear stress $\left(\sigma_{12}\right)$ and normal stress differences $\left(\mathrm{N}_{1}=\right.$ $\left.\sigma_{11^{-}} \sigma_{22}, \mathrm{~N}_{2}=\sigma_{22}-\sigma_{33}\right)$. The flow direction and the perpendicular surface at which the fluid is sheared are indicated by 1 and 2, while 3 is the neutral direction [1]. $\mathrm{N}_{1}$ is the larger of two normal stress differences and it is responsible for rod climbing behaviour of viscoelastic materials. In the case of isotropic materials, the magnitude of $\mathrm{N}_{1}$ is greater or equal to zero and in parallel plate and cone and plate rheometers, it pushes apart the contact surfaces. The magnitude of the second normal stress difference $\left(\mathrm{N}_{2}\right)$ is usually much smaller than $\mathrm{N}_{1}$ and it is always a negative value. According to Keentok et al. (1980) and Ramachandran et al. (1985) the relationship between $\mathrm{N}_{1}$ and $\mathrm{N}_{2}$ is given by $0.05<-\mathrm{N}_{2} / \mathrm{N}_{1}<0.3[2,3]$. It must be taken into consideration that the measurement of the transient normal stress differences $\left(\mathrm{N}_{1}\right.$ and $\mathrm{N}_{2}$ ) is rather challenging due to the errors caused by the temperature variations and compliance of the instrument [4]. Furthermore, the "wall-slip" effect could cause significant inaccuracy in step-strain experiments. The true strain could be even lower than the nominal strain caused by the displacement of the surfaces of rheometers' fixture. Therefore, when the Lodge-Meissner relation is not satisfied, it could be deduced that the wall-slip effect has occurred, hence, the nominal strain would be replaced by the stress ratio when reporting the first normal stress difference and shear stress data.

Liquid crystals (LCs) are in a state of matter that have properties similar to conventional liquids and solid crystals [5]. LCs have long-range molecular order somewhere between the crystalline state, which exhibits three-dimensional order, and the disordered isotropic fluid state [6]. The molecules in a crystal are ordered whereas in a liquid state they are randomised. In general, Liquid Crystal Polymers (LCPs) can be classified as Thermotropic Liquid Crystal Polymer (TLCP) and Lyotropic Liquid Crystal Polymer. LCPs, whose phase transition to the liquid crystalline phase occurs due to change in temperature, are called TLCP. On the other hand, those whose phase transition occurs as a result of the alteration of the polymer concentration in a solvent (as well as temperature), are called lyotropic liquid crystal [7]. Most liquid crystalline molecules are highly anisotropic and may be regarded as rigid rods. In general, the units of liquid crystal compounds consist of two or more aromatic rings, i.e. the 
longer the ring, the higher the melting temperature of LCPs [8]. The linking group makes an important contribution to the phase transition and superior physical properties.

The Liquid crystalline phase is also known as mesomorphic phase or mesophase. Mesomorphic phase can be defined as the intermediate form between liquid and crystal [9]. In nematic mesophase phase, the molecules have no positional order but have a long range orientational order [10]. The rod-like molecules of LCPs [11] showed that shear induced transitions between tumbling, i.e. rotation of molecules at their own axis, wagging and flow aligned regimes are responsible for the unusual behaviour of the first normal stress differences [12, 13]. Rienacker and Hess (1999) studied shear induced orientational dynamics of nematic liquid crystals, where they observed different shear rate regions for different types of orientation [14]. The rod-like molecules start to tumble when subjected to shear deformation and they rotate from tumble to wagging region at the critical shear rate. The transformation from wagging to flow aligned region occurs as the shear rate increases. The theoretical prediction from the Doi theory showed good agreement with experimental data at low shear rate region $[13,15]$.

The negative normal stress difference is one of the most important rheological characteristics of LCPs. Kiss and Proter (1978) reported the experimental evidence of negative first normal stress difference of lyotropic LCPs for the first time [16]. Subsequent evidence of negative first normal stress difference $\left(\mathrm{N}_{1}\right)$ of lyotropic solutions soon followed in other studies [12, $13,17]$. The negative behaviour of $\mathrm{N}_{1}$ is common to lyotropic system whereas it is very unlikely for thermotropic LCPs.

Marrucci and Guido (1993) first explained extensively the mechanism of negative normal stress difference [18]. For lyotropic LCPs, the negative normal stress is observed in the intermediate shear rate region, i.e. 10-100 $\mathrm{s}^{-1}$. The ellipsoid shape of domain becomes deformed and the rotation of molecule tends to become perpendicular to the flow axis at significantly large shear rates. Additionally, considering the rotation of molecules at their own axis, molecules rotate from tumbling to wagging state [13]. Hence, the value of $\mathrm{N}_{1}$ becomes negative at reasonable shear rates. However, when the shear rate is high, the value of $\mathrm{N}_{1}$ becomes positive. This will occur when the strength of the flow has become so large that tumbling is suppressed altogether, and the molecules increasingly align in the shear direction [18]. Besides, the value of $\mathrm{N}_{1}$ also depends on the concentration of fillers within LCP matrix. Accordingly, Beak and Magda (1993) reported the change of $\mathrm{N}_{1}$ behaviour of 
lyotropic LCPs from negative to positive as a function of shear rate as well as filler concentration[12].

It has been observed that this anomalous orientation was enhanced due to the presence of the filler. The interaction between the fibre-like fillers offsets the force attempting to align the fibres with the direction of the flow where substantial resistances to deformation were observed at low shear rates [19]. The stated interactions are overcome due to the orientation of fibres in the direction of flow at higher shear rates; hence, the arrangement of LCPs matrix and fibres is disrupted [20]. For filled LCPs, negative first normal stress differences were observed in the low shear rate regions. The existence of negative first normal stress differences in LCPs arises great interest in their rheological studies [21].

Due to enormous measurement difficulties, the elasticity of melt polymeric systems has not been studied to the same extent as shear measurements [22, 23]. Some of the common methods of evaluation of the elasticity include normal force measurements, capillary flow entrance pressure drop and extrudate swell. One approach to measure the elasticity of melt polymers in steady shear experiment is to measure $\mathrm{N}_{1}$ of the samples.

It is well known that the first normal stress difference $\left(\mathrm{N}_{1}\right)$ of polymer melts or solutions increases when subjected to shear deformation. Nevertheless, the impact of filler/nanofiller loading on this rheological phenomenon is insufficiently known and anomalous behaviours of $\mathrm{N}_{1}$ have been widely reported in literature.

The authors of this study have already performed exhaustive morphological, mechanical, shear rheological and thermal characterization of PLA/NGP systems [24-26]. In this study, the first normal stress difference behaviours of polylactide and nanographite platelet bionanocomposites have been studied. In addition, $\mathrm{N}_{1}$ behaviour of glass filled liquid crystalline polymers (LCPs) has also been explored. Overall, the authors have investigated the prospective existence of a correlation between $\mathrm{N}_{1}$, level of filler content and shear stress in those polymeric systems. 


\section{Theoretical Backgrounds}

\section{$\underline{\text { Rheological Definition of First Normal Stress Difference }\left(N_{1}\right)}$}

In the zero-shear viscosity region of steady shear rheology, where shear viscosity, i.e. $\eta=\sigma_{12} / \dot{\gamma}$, becomes independent of shear rate, the first and second normal stress differences at low shear rate region approach the limit of $\mathrm{N}_{1}, \mathrm{~N}_{2} \propto \dot{\gamma}$ and consequently, the normal stress coefficients $\left(\psi_{1}, \psi_{2}\right)$ approach constant values:

$\psi_{1} \equiv \frac{\sigma_{11}-\sigma_{22}}{\dot{\gamma}^{2}}, \psi_{2} \equiv \frac{\sigma_{22}-\sigma_{33}}{\dot{\gamma}^{2}}$

Although at low shear rates $\eta$ and $\psi_{1}$ approach constant values $\left(\eta_{0}, \psi_{1}, 0\right)$, they exhibit a continuous and dramatic decrease in size at higher shear rates, i.e. nonlinear shear thinning behaviour. The deviation of zero-shear behaviour occurs when shear rate $(\dot{\gamma})$ and consequently shear strain $(\gamma=\dot{\gamma} t)$ are beyond the limit of their linear viscoelastic region. The steady state zero-shear viscosity $\left(\eta_{0}\right)$ and $\psi_{1,0}$ can also be evaluated from low frequency linear viscoelastic measurements via dynamic frequency sweep analysis:

$$
\begin{aligned}
& \eta \dot{\gamma})=\eta^{\prime}(\omega) ; \text { as } \omega=\dot{\gamma} \rightarrow 0 \\
& \psi_{1}(\dot{\gamma})=\frac{2 G^{\prime}(\omega)}{\omega^{2}} ; \text { as } \omega=\dot{\gamma} \rightarrow 0
\end{aligned}
$$

Following step shear strain measurements of polymer melts and solutions, the shear stress and the first normal stress difference $\left(\mathrm{N}_{1}\right)$ can be correlated through the Lodge-Meissner relationship [27]:

$$
N_{1}=\sigma_{12} \gamma=\gamma^{2} G(t)
$$

Where, $\gamma$ is the shear strain and $G(t)$ is the relaxation modulus. Lodge-Meissner rule suggests that at sufficiently low strains, the stress ratio $\left(N_{1} / \sigma_{12}\right)$ tends to become equal to the strain 
[27]. Thus, in the case of isotropic elastic solids, the stress ratio is always equal to strain while the Doi-Edwards theory predicts the equality of stress ratio and strain [28]:

$\frac{N_{1}(t, \gamma)}{\sigma_{12}(t, \gamma)}=\gamma$

Subsequently, when the time-strain superposability is applicable (thermo-rheologically simple materials), the transient first normal stress difference in terms of shear damping function, i.e. $\mathrm{h}(\gamma)$, becomes [28]:

$$
\begin{aligned}
& N_{1}=\gamma^{2} h(\gamma) G(t), \\
& \psi_{1}(t, \gamma) \equiv \frac{N_{1}}{\gamma^{2}}=h(\gamma) G(t)
\end{aligned}
$$

The above correlations (Eqs. 6,7) have successfully described the experimental data for LDPE for strain up to 30 , polybutadiene solution for strain up to 3.3 and polystyrene solution for strain up to 8 [28-31].

\section{Mechanisms of Steady Shear Rheology in Polymer Composites}

In polymer nanocomposites (PNCs), where polymer-adsorption induced interparticle bridges are formed through polymer-mediated interparticle interactions, the influence of particles on polymer dynamics is considerably higher than the colloidal limits where the interparticle distances are larger than the size of polymers [32]. In order to investigate the steady shear rheological properties of polymeric systems from macromolecular structure and relaxation behaviour standpoint, it is indispensable to investigate the zero-shear viscosity $\left(\eta_{P}^{0}\right)$ and first normal stress difference of polymer matrices in linear viscoelastic region through Rouse model [33]:

$\eta_{P}^{0} \sim \tau_{0} N_{P}$

$N_{1 P}^{0} \sim N_{P}^{3}\left(\dot{\gamma} \tau_{0}\right)^{2}$ 
Where $\tau_{0}$ is the relaxation time of the polymer chains, $\mathrm{N}_{\mathrm{p}}$ is the number of segments in the polymer chain and $\dot{\gamma}$ is the shear rate. Alternatively, the finite extensibility of polymer chains results in the nonlinear viscoelastic behaviours of neat polymers. The critical shear rate $(\ddot{\gamma})$, i.e. the onset of nonlinear shear thinning region $\left(\dot{\gamma}>{ }^{* *}\right)$, can be described as the shear rate at which the extension of chains in the direction of flow brings about a concomitant contraction in the gradient direction [32]. According to Semenov and co-workers [34, 35], the critical shear rate, viscosity and first normal stress difference are predicted as:

Critical shear rate,

$\stackrel{\bullet}{\gamma} \sim \frac{1}{\tau_{0}} N_{P}^{-3 / 2}$

The relationship between shear viscosities in linear and non-linear viscoelastic regions,

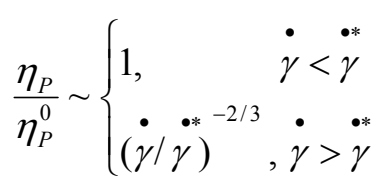

The relationship between first normal stress differences in linear and non-linear viscoelastic regions,

$\frac{N_{1 P}}{N_{1 P}^{0}} \sim \begin{cases}1, & \dot{\gamma}<{ }^{* *} \\ \left.\dot{\gamma} / \ddot{\gamma}^{* *}\right) & , \dot{\gamma}>\ddot{\gamma}^{-* / 3}\end{cases}$

Semenov model of first normal stress difference based on the critical shear stress:

$N_{1 P} \sim\left(\frac{\sigma}{\sigma^{*}}\right)^{2}$ where $\sigma^{*}=\eta_{P}^{0} \stackrel{*}{\gamma}, \sigma=\eta_{P} \dot{\gamma}$

The zero-shear viscosity of PNC suspensions has exhibited growth as a result of the addition of hard-sphere colloidal particles. The particles volume fraction $(\phi)$ and the boundary condition at the solid interface are the only governing elements of the magnitude of such growth. The following relationship determines this trend in dilute concentrations [36-39]:

$\eta_{r} \equiv \frac{\eta}{\eta_{P}}=1+\phi[\eta]$ 
Where $\eta_{\mathrm{r}}$ is relative viscosity, $\eta$ the viscosity of the suspension form of PNCs, $\eta_{\mathrm{P}}$ is the viscosity of solvent (pure polymer), $[\eta]=\frac{5}{2}\left(\frac{1+2 \lambda}{1+5 \lambda}\right)$ is the Einstein coefficient of suspension and $\lambda$ is the slip length which represents the stress transfer boundary condition at the particlepolymer interface ( $0 \leq \lambda \leq \infty$ for no-slip to perfect slip situations, respectively). However, for more concentrated suspensions the following empirical equation was proposed by Krieger and Dougherty [40, 41]:

$\eta_{r}=\left(1-\frac{\phi}{\phi_{\max }}\right)^{-[\eta] \phi_{\max }}$

Where, $\phi_{\max }=0.63-0.68$, embodies the maximum packing fraction for the colloids and it could provide an acceptable fit to the shear viscosity as a function of filler concentration over wide range of volume fractions $(\phi)$ [32].

\section{Dependence of Shear Viscosity on Shear-Rate}

Pryamitsyn and Ganesan (2006) investigated the steady shear rheology of a model system of well-dispersed spherical nanoparticles in unentangled polymer matrix, i.e. short polymer chains where topological constraints between polymers do not manifest in the macroscopic rheology [33], through computational simulation. Their shear viscosity results were consistent with PNC systems and filled polymer melts of different studies, where the addition of nanofillers caused an accentuated shear thinning behaviour and finally asymptoted at higher shear rates to a filler content independent viscosity behaviour [42-46]. Prior to Pryamitsyn and Ganesan's modelling investigation, the mentioned observations were explained in the literature either as the existence of higher shear rates in the gaps between nanofillers leading to faster shear thinning of the polymeric matrix or the occurrence of agglomerated networks of the colloidal particles which could be also manifested as the yield stress at low shear rate [45, 47-49]. Nevertheless, due to the absence of yield stress in Pryamitsyn and Ganesan (2006)'s simulation of well dispersed PNC model, the contribution of particle aggregation to enhanced shear thinning behaviour was excluded [32]. 
They also reported that the addition of nanoparticles to PNCs with chain lengths $\mathrm{N}_{\mathrm{p}}=4,16$ and 24 , caused reduction in the elasticity of samples $\left(\mathrm{N}_{1} / \sigma=\right.$ recoverable strain or Weissenberg number). Their results showed that in diluted systems, the addition of nanofillers initiated a reduction in $\mathrm{N}_{1}$ magnitudes, while for concentrated systems with shortest chain length $\left(\mathrm{N}_{\mathrm{p}}=4\right)$ the decrease in $\mathrm{N}_{1}$ was associated with positive and negative values at low and high shear rate regions, respectively. On the other hand, the first normal stress behaviour of concentrated suspensions with longer polymer chains $\left(\mathrm{N}_{\mathrm{p}}=16,24\right)$ exhibited shear stress dependence of $\mathrm{N}_{1}$ governed by exponent $n$ of the following empirical Mall-Gleissle relationship at low shear stresses $(0.01<\sigma<1)[50]$ :

$$
N_{1}(\phi, \sigma)=A(\phi) \sigma^{n}
$$

Where, $A$ is a volume fraction dependent parameter which characterizes the particle contribution to $\mathrm{N}_{1}$ and $n$ is a volume fraction independent exponent expressing the rheology of the samples. Conversely, the occurrence of asymptote to a concentration independent value was evident at higher shear stresses $(\sigma>1)$.

In summary, the reduction in $\mathrm{N}_{1}$ as a result of the addition of nanofillers could be categorized into the following three regimes: i) In short chain-concentrated (SC) systems, the decrease in $\mathrm{N}_{1}$ is positive at low and negative at high shear rate regions resembling the behaviour of colloidal hard-sphere dispersion in simple fluids [32], (ii) For long chain-concentrated (LC) systems, the reduction in $\mathrm{N}_{1}$ is primarily governed through exponent $n$ (Eq. 16), indicating the shear stress dependence of first normal stress difference while it becomes concentration independent at higher shear rates, and (iii) Dilute systems of both small and large polymeric chains (SD and LD, respectively) exhibit similar behaviours at which exponent $\mathrm{n}$ remains relatively constant while $\mathrm{A}(\phi)$ function monotonically decreases with volume fraction. These three regimes have shown consistency with earlier studies conducted on PNCs and filled polymer systems where the reductions in $\mathrm{N}_{1}$ occurred as a result of filler loading. Aral and Kalyon (1997) reported negative $\mathrm{N}_{1}$ values at high concentrations of glass beads in polymeric matrix (SC system) [51]. Krishnamoorti et al. (2001) noticed insignificant reduction of $\mathrm{N}_{1}$ upon addition of small loading fraction of clay in polymeric matrix (LD system) [52]. MallGleissle et al. 2002 demonstrated the applicability of Eq. 16 with a constant exponent $n$ and $a$ decreasing $A(\phi)$ function in low volume fraction of glass beads in silicon oil (SD systems) [50]. White and Tanaka (1981) suggested that the yield stress of matrix is the principal contributing factor behind $\mathrm{N}_{1}$ reduction of samples upon which the fading $\mathrm{N}_{1}$ is due to 
reaching yield stress. Nonetheless, the absence of yield stress in Pryamitsyn and Ganesan (2006)'s simulations refuted this hypothesis [53]. Mall-Gleissle et al. (2002) divided the overall first normal stress difference of the samples into two contributing elements; small and negative values of particles' $\mathrm{N}_{1}$ and positive $\mathrm{N}_{1}$ values of polymeric matrix. Though, their postulation could not provide adequate explanations for volume fraction independent long chain-concentration (LC) systems [50].

\section{Experimental}

\section{Materials}

$P L A$ and NGP

Grade 3051D Poly (L,L-lactide)- (PLA) was supplied by NatureWorks LLC with melt index and specific gravity of $10-30 \mathrm{~g} / 10 \mathrm{~min}$ and 1.24 , respectively. The molecular characteristics of PLA 3051D were reported as: weight average molecular weight $\left(\mathrm{M}_{\mathrm{w}}\right)=92.5 \times 10^{3} \mathrm{~g} / \mathrm{mol}$, $\mathrm{M}_{\mathrm{w}} / \mathrm{M}_{\mathrm{n}}=1.82, \mathrm{~T}_{\mathrm{g}}=55^{\circ} \mathrm{C}, \mathrm{T}_{\mathrm{m}}=150{ }^{\circ} \mathrm{C}$, Intrinsic viscosity $(\eta)=89.5 \mathrm{~mL} / \mathrm{g}$, hydrodynamic and gyration radii $\left(\mathrm{R}_{\mathrm{h}}, \mathrm{R}_{\mathrm{g}}\right)=10.6,16.6 \pm 7.1 \mathrm{~nm}$ and with relationship between zero shear viscosity and molecular weight of $\left[\eta_{0}\right]_{T_{r}=180^{\circ} \mathrm{C}}=10^{-14.2} M_{w}^{3.4}$ [54]. Nanographite platelets (NGPs) were supplied by XG Sciences, Inc. US Michigan and the grade of NGP used for this study was "M" with the following characteristics: average thickness of approximately $6-8$ nanometers and a typical surface area of 120 to $150 \mathrm{~m}^{2} / \mathrm{g}$. According to the material data sheet, Grade M (xGnp-M) was available with average particle diameters of 5,15 or 25 microns.

\section{$L C P$}

Four aromatic nematic thermotropic LCPs in the form of pellets were selected for this study. Only the major constituents of LCPs are mentioned due to propriety rights. The following nomenclatures are used for different filled and unfilled LCPs in this study.

1. LCP Polymer A unfilled (copolymer of p-hydroxy benzoic acid (HBA), 6- 
hydroxy-2 naphthoic acid (HNA), terephthalic acid (TA) and Amide II)

2. LCP Polymer A filled with $35 \mathrm{wt} \%$ glass fibre.

3. LCP Polymer B unfilled (copolymer of p-hydroxy benzoic acid (HBA), 6-

hydroxy-2 naphthoic acid (HNA) and terephthalic acid (TA)

4. LCP Polymer B filled with $30 \mathrm{wt} \%$ glass fibre.

\section{Processing}

$P L A / N G P$

PLA pellets and nanographite platelets (NGP) were dry mixed in the desired composition before melt blending in $700 \mathrm{~g}$ batches. Table 1 shows the compositions (nominal $\mathrm{wt} \%$ ) and the codes of neat PLA and PLA/NGP samples (hereafter, samples are referred to according to their sample codes).

Samples were melt-blended in a Brabender Twin Screw extruder. The speed and temperature of the extruder were set at $180{ }^{\circ} \mathrm{C}$ and 40 RPM. Dried pellets were compression moulded (temp. $=180{ }^{\circ} \mathrm{C}$, compression $=80 \mathrm{kN}$ for 5 minute) into $2 \mathrm{~mm}$ thick circular plaque with 20 $\mathrm{mm}$ diameter specimens.

$L C P$

The LCP materials were dried in a vacuum dryer at $120{ }^{\circ} \mathrm{C}$ for eight hours to achieve target moisture content of less than $0.02 \%$ prior to use. These dried materials were then compression moulded within the parameters of processing temperature window as specified by the supplier of these materials. The $2 \mathrm{~mm}$ thick compression moulded samples were then cut into $25 \mathrm{~mm}$ diameter discs.

\section{Rheological measurements}

\section{Steady Shear Rheology}

PLA/NGP 
Steady shear measurements were conducted through an Advanced Rheometrics Expansion System (ARES) rheometer (TA Instruments) with parallel plate geometry using $25 \mathrm{~mm}$ diameter plates. A force transducer with a torque range of 0.2 to $200 \mathrm{~g} . \mathrm{cm}$ was applied to all measurements. All rheological tests were performed at the working temperature of PLA (180 $\left.{ }^{\circ} \mathrm{C}\right)$. The tests were executed within the strain rate of $0.01-100 \mathrm{~s}^{-1}$ to measure 20 points per decade. The delay before measurement was set at 15 seconds and the delay of measuring time of each point was set at 45 seconds.

\section{$L C P$}

Shear rheological properties were studied via an ARES rheometer for both dynamic and steady shear modes with parallel plate geometry. The tests were conducted using $25 \mathrm{~mm}$ diameter plates at temperatures between $330{ }^{\circ} \mathrm{C}$ and $350{ }^{\circ} \mathrm{C}$ for the various LCP materials. All measurements were performed using a force transducer with a range of 0.2 to $200 \mathrm{~g}$-cm torque. Prior to any test, the zero gap between the parallel plates was calibrated at the required temperature. For both filled and unfilled LCP-A samples, the temperature was maintained at $350{ }^{\circ} \mathrm{C}$ while the testing temperature of for LCP-B (filled and unfilled) samples was maintained at $330{ }^{\circ} \mathrm{C}$. Prior to each test, the samples were placed between preheated fixtures for 10 minutes to reach thermal equilibrium and subsequently the gap was set. The steady shear rheological measurement were conducted at a shear rate range of 0.01 to $10 \mathrm{~s}^{-1}$ in order to avoid the occurrence of sample rupture and slippage at high shear rates, 


\section{Results and Discussion}

\section{PLA/NGP}

Figure 1 shows the steady shear viscosity and first normal stress difference of PLA02 (an exemplary PNC) versus shear rate. It clearly demonstrates that the shear thinning behaviour of shear viscosity $(\eta)$ and stress $(\sigma)$ became evident as the shear rate progressively increased (shear rate $>1 \mathrm{~s}^{-1}$ ). However, $\mathrm{N}_{1}$ exhibited an utterly different behaviour upon which it increased steadily and reached a steady state plateau at comparatively high shear rates (10$100 \mathrm{~s}^{-1}$ ) where no reliable shear viscosity data was available. Therefore, this manifestation of steady state and near equivalence behaviour of $N_{1}$ at high shear rate region (shear rate $>1 \mathrm{~s}^{-1}$ ) could be another indication of the near-independence of $\mathrm{N}_{1}$ behaviour of polymer matrix from both shear rate and the incorporated nanofillers; regardless of their level of loading and dispersion in the nonlinear viscoelastic region, i.e. ( ( hear rate $>1 \mathrm{~s}^{-1}$ ).

Figure 2 demonstrates the steady shear viscosity of neat PLA and PLA/NGP composites. At low shear rate region $\left(<2 \mathrm{~s}^{-1}\right)$, all samples exhibited Newtonian-like behaviour. However, the zero-shear viscosity of samples increased according to the amount of their filler contents. In a study conducted by Ramsay (1986), the shear viscosity of intercalated and delaminated poly(dimethyl siloxane)/2M2T-MMT composites with varying silicate contents were measured at $28{ }^{\circ} \mathrm{C}[55,56]$. The absence of Newtonian behaviour at low shear rate region, i.e. the occurrence of shear thinning behaviour, of intercalated poly (dimethyl siloxane) composites was associated with the alteration of the relaxation dynamics of the polymer matrix due to the highly anisotropic intercalated layered silicate particles leading to shear thinning behaviour of composites at all shear rates [56]. The alteration of the relaxation dynamics occurs at long relaxation times (corresponding to low shear rate region) where the behaviour of relaxation modulus determines the likelihood of the occurrence of the zero shear viscosity. Nonetheless, fully delaminated poly (dimethyl siloxane)/2M2T-MMT nanocomposites exhibited a systematic increase in their steady-shear viscosity, yet they obeyed Newtonian behaviour in low shear rate region. Sinha Ray (2006) explained that this behaviour indicates that the delaminated filler layers do not affect the relaxation dynamics of polymer matrix, thus, the rheological behaviours of those nanocomposites exhibited similarities to the conventional filler filled systems [56]. However, Pryamitsyn and Ganesan 
(2006) ascribed the overall shear stress of PNC suspensions to polymer-polymer (PP), particle-particle (CC) and particle-polymer (CP) interactions [32]. The resulting stress due to PP interactions determines the polymeric matrix rheological responses, CP exhibits the hydrodynamic (frictional) contribution in PNCs and CC represent the stress resulting from direct or collisional interactions between nanoparticles. For dilute filler concentrations, PP interactions dominate the overall stress contribution while at higher concentrations, CC's role becomes prominent up until it ultimately controls the overall stress contribution at highest filler concentration ( $\phi=0.5)$. The matrix chain length determines CP's involvement to overall stress, i.e. for a given volume fraction $(\phi), \mathrm{CC}$ or PP interactions is dominant in long chain polymers at low rates while mere PP interactions are responsible at high shear rate region. The formation of the transient polymer network is due to CP frictional interactions and it markedly slows down the polymer dynamics while at the same time the incorporation of excess nanoparticles results into additional nodes of immobilization (entanglements) in the matrix leading to the rise in the viscosity of polymer matrix as well as their elastic modulus $[33,57]$. Therefore, the mobility reduction caused by the artificial increase of entanglements (transient networks) induces growth in the longest relaxation times (controlling the onset of shear thinning behaviour) which subsequently leads to a noticeable reduction in the critical shear rate (Eq. 10). Table 2 confirms the applicability of this conjecture to this study's neat PLA and PLA/NGP composites where the results demonstrated both significant drops in the critical shear rate of the composites and notable escalations in the zero-shear viscosity of PLA/NGP composites compared to neat PLA. As previously mentioned, the particle-polymer (CP) interactions are responsible for the hydrodynamic effects governed by the "slip of the polymer on the particle surface mechanism" which is the formation of hydrodynamic slip at the interfacial surface between polymer and smooth solid surface of particles [32, 58-61]. Brochard and De Gennes (1992) proposed the following relationship between the matrix viscosity and slip length $(\lambda)[58]$ :

$\lambda=\eta_{P}^{0} / k$

Where, $k$ represents the segmental viscosity at the particle surface. Due to the direct correlation between polymer viscosity and chain length in Eq. 8, the slip length $(\lambda)$, in Einstein coefficient ([ $\eta])$, and consequently the CP interaction are expected to grow with the increase in polymer chain length $\left(N_{P}\right)$, whilst, Einstein coefficient and subsequently the relative viscosity (Eq. 14) of PNCs drops significantly [32]. Therefore, the observation of 
Newtonian-like behaviour in Figure 2 may indicate that NGP fillers of this research could have been comparatively delaminated within PLA matrix to follow the mentioned conjecture of PNC suspensions. The filler content-dependent shear thinning behaviour of the samples at critical shear rates (figs. 1 and 2) could demonstrate the direct correlation between the level of loading and the characteristic relaxation times (longest relaxation times) of the PNCs. As demonstrated in Eq. 10, the critical shear rate is proportional to the inverse of the characteristic relaxation time $\left(\tau_{0}\right)$ of polymeric systems. Therefore, the progressive decrease of the critical shear rates of PNCs could be attributed to the growth of the longest relaxation times of the composites at higher filler contents, which is also indicative of the continual transitions from liquid-like to solid-like behaviours at higher filler contents. For instance, the longest relaxation times of neat PLA and PLA05 are 0.06 and $0.18 \mathrm{~s}$ when their corresponding critical shear rates are 2.2 and $1.3 \mathrm{~s}^{-1}$, respectively (Table 2).

Figures 3 and 4 illustrate the first normal stress difference of the samples versus steady shear rate and shear stress, respectively. Choi et al. (1999) emphasized the importance of the investigation of $\mathrm{N}_{1}$ as a function of shear stress (rather than rate) due to the possible lack of continuity in the velocity gradient (i.e. shear rate) at the solid-liquid interface in the absence of the occurrence of slippage between the phases [62]. The results exhibited a strong dependence of $\mathrm{N}_{1}$ behaviour on NGP filler content. According to Bhattacharya et al. (2007), the contributing factors to the elasticity of the filled systems include filler size, filler content and their geometry. Isotropic fillers such as glass beads, carbon black, $\mathrm{CaCO}_{3}$ and $\mathrm{TiO}_{2}$ have demonstrated reduction in the elasticity of their composites compared to neat polymeric systems [63]. On the other hand, White et al. (1980) related the observed increase in $\mathrm{N}_{1}$ of fibre-like filler composites to the strong orientation of nanofillers in the direction of flow leading to the hydrodynamic particle effect of fibre-like fillers [64]. Khan and Prud'Homme (1987) associated the lower elasticity of isometric-filler polymer composites to their normal component of stress becoming zero when the shear component retains a finite value; hence, lower elasticity [65]. However, in the case of anisometric fillers (e.g., fibres and platelets), the elasticity is escalated due to the increase in the $\mathrm{N}_{1}$ of their composites. Although fillers' morphology plays an important role in elasticity of the composites, excessive (higher than optimum) amount of filler concentration has an adverse effect on the elasticity of these systems $[66,67]$. This rise in rigidity as a result of excessive filler loading is due to the reduced mobility of polymer chains in the presence of the fillers $[22,66]$. The dispersion of fillers within polymeric matrix can also play an important part in the elasticity of polymer 
composites. The near independence of $\mathrm{N}_{1}$ from filler content at all shear rates in intercalated PNCs has been associated with the intercalation of fillers in the composites, resulting from the preferential orientation of two dimensional nanofillers in the direction of flow which could diminish the effect of CC and CP interactions and their influence to elasticity $[52,68]$. Nonetheless, in a study conducted by Prasad et al. (2005) on exfoliated ethylene-vinyl acetate (EVA)/layered silicate nanocomposites, $\mathrm{N}_{1}$ demonstrated an inverse relationship with filler contents; i.e. the magnitude of $\mathrm{N}_{1}$ declined as the silicate filler content increased. They associated this behaviour to the reduced mobility of polymer chains due to the enhanced interactions between silicate fillers and polymer chains [69].

Alternatively, Pryamitsyn and Ganesan (2006) showed through computational simulation that the polymeric $\mathrm{N}_{1}$ behaviour is independent from the matrix relaxation time and the particle related interactions (CC, CP) in Semenov model (Eq. 13). Furthermore, it is important to note that the particle influence ( $\mathrm{CP}$ and $\mathrm{CC}$ ) on the first normal stress difference is insignificant at low particle loadings, hence, the anomalous alterations in $\mathrm{N}_{1}$ could be due to the "dilution of polymer from the matrix" [32]. This is in accordance with the previously mentioned conjecture of the relationship between the dependence of $\mathrm{N}_{1}$ on the level of dispersion in PNC systems as agglomerated and intercalated particles may not contribute adequately to the overall dilution of polymeric matrix whereas exfoliated (delaminated) particles could effectively dilute the polymer from its matrix. In brief, the dilution of polymeric matrix as a result of the exfoliation of nanofillers could lead to the alteration of $\mathrm{N}_{1}$ behaviour of neat polymers in PNCs.

In a study conducted by Wang et al. (2006), the first normal stress difference of polystyrene/carbon nanofibres (PS/CNFs) with filler contents $0-10 \mathrm{wt} \%$ was investigated [70]. The samples were fabricated through melt blending (MB) and solvent casting (SC) mixing techniques and the morphological characterization of samples exhibited a fourfold increase $(160 / 40)$ in the aspect ratio of SC systems, i.e. considerably higher uniformity and enhanced dispersion of CNFs in the SC composites compared to their MB counterparts. Accordingly, the $\mathrm{N}_{1}$ measurements of neat PS and its MB composites displayed independence from CNF filler contents. On the other hand, the $\mathrm{N}_{1}$ magnitude of SC composites exhibited a robust dependence on the level of filler loading in shear rate spectrum of 0.01-10 s $\mathrm{s}^{-1}$ where $\mathrm{N}_{1}$ demonstrated a direct correlation with the amount of filler content. They reported that the dependence of $\mathrm{N}_{1}$ on CNF filler contents progressively diminished up to shear rate $10 \mathrm{~s}^{-1}$ where no effect was observed afterwards [70]. Overall, their findings were 
another indication of validity of the previously mentioned theories explaining the direct influence of the level of delamination of nanofillers on the first normal stress difference of PNCs. Nonetheless, the anomaly of such interaction was still conserved through the escalation of $\mathrm{N}_{1}$ due to the increase of filler content.

\section{Anomalous Behaviour of PLA/NGP Composites}

The dependence of $\mathrm{N}_{1}$ behaviour on the NGP loading at low shear rate region $\left(<2 \mathrm{~s}^{-1}\right)$ could indicate that the dispersion of NGP within PLA matrix has reached some level of exfoliation. However, the drop in $\mathrm{N}_{1}$ of composites did not reveal a consistently direct relationship with nanofiller content; the $\mathrm{N}_{1}$ behaviour of PLA01 did not exhibit a moderate decrease compared to neat PLA while PLA02 displayed a considerable increase from neat PLA. However, the magnitude of $\mathrm{N}_{1}$ exhibited a significant reduction for PLA03 and PLA05 whilst the lowest $\mathrm{N}_{1}$ value of samples was recorded for PLA03. On the other hand, the magnitude of first normal stress difference of all samples reached a near equivalence and independence at higher shear rates $\left(>2 \mathrm{~s}^{-1}\right)$ and shear stresses $\left(>2 \times 10^{03} \mathrm{~Pa}\right)$. According to Sinha Ray (2006) and Giannelis et a. (1999) near equivalence and independence of $\mathrm{N}_{1}$ at higher shear rates could be associated with the preferential orientation ability of the two-dimensional nanofiller layers to the direction of shear flow $[56,71]$.

In order to mathematically investigate the dependence of $\mathrm{N}_{1}$ behaviour of PLA/NGP composites on filler loading through Semenov model (Eq. 13), the shear rheological viscosities of PLA/NGP composites were fitted into Carreau-Yasuda (1979) Model utilizing RSI Orchestrator software. Carreau-Yasuda model is a five-parameter model which is known as the most reliable model for estimating the zero-shear viscosity of polymer melts [72]:

$\frac{\eta-\eta_{\infty}}{\eta_{\circ}-\eta_{\infty}}=\frac{1}{\left[1+\tau(\dot{\gamma})^{a}\right]^{\frac{(1-n)}{a}}}$

Where $\tau(\mathrm{s})$ is the characteristic or relaxation time, $\eta_{0}(\mathrm{~Pa} . \mathrm{s})$ is the zero-shear viscosity and $n$ is a dimensionless parameter which determines the slope of shear thinning (non-Newtonian) region, i.e. slope $=n-1$ where $0 \leq n<1$; special case: Newtonian flow, where $n=1$. The 
parameter $a$ improves the depiction of the transition zone between Newtonian and the shear thinning regions, hence, it denotes the magnitude of the shear rate corresponding to the onset of shear thinning behaviour, i.e. $\dot{\gamma}^{*}$. Moreover, $\eta_{\infty}$ is the shear viscosity at very high shear rates which is considered zero in this study due to its inaccessibility through conventional stress/strain rheometers.

Table 2 demonstrate the computed model parameters of the samples via Carreau-Yasuda and Semenov models. The zero-shear viscosity of samples demonstrated a noticeable enhancement as the content of NGP fillers increased. Although the critical shear rate showed an inverse relationship with the level of loading, the critical stress did not exhibit a remarkable dependence on the filler contents. Moreover, the characteristic time $(\tau)$ of samples displayed a threefold upsurge when the filler content of neat PLA was increased to 3 and $5 \mathrm{wt} \%$. Inclusive theoretical explanations of these observed rheological behaviours have been explained in the former sections of this study.

Figure 5 demonstrates the dependence of the first normal stress difference on shear rate and filler concentration of the samples. Apart from the anomalous increase in the $\mathrm{N}_{1}$ of PLA02, the rest of the samples exhibited a moderate decrease in their first normal stress difference as the NGP filler content was raised to $5 \mathrm{wt} \%$. The minimum value of $\mathrm{N}_{1}$ was recorded at PLA03 which was consistent with the previously reported rheological and mechanical, i.e. via slope $(\alpha)$ and Young's modulus analysis, percolation thresholds of the samples [24-26]. However, the relationship between $\mathrm{N}_{1}$ and shear rate did not display anomaly when all samples demonstrated a direct correlation with the magnitude of the shear rate.

Figure 6 displays the modelled apparent shear stress exponent $\left(N_{1 P} \sim\left(\frac{\sigma}{\sigma^{*}}\right)^{2}\right)$ values of neat PLA and PLA/NGP composites via Semenov model. This chart clearly shows a power law increase in the magnitude of $\mathrm{N}_{1}$ versus shear stress, however, it does not significantly demonstrate the dependence of the apparent shear stress exponent on NGP filler contents. Since the polymeric chain lengths remained constant for all samples, Semenov model could mainly suggest the occurrence of polymeric contribution (PP interactions) to the shear stress dependence of $\mathrm{N}_{1}$. The discrepancy between the theoretical modelling and the experimental results (Figures 6 and 4 ) is more accentuated after the termination of the power law region ( $\sigma$ $>30 \mathrm{~Pa})$ while zero-first normal stress differences $\left(N_{1}^{0}\right.$ at $\left.10>\sigma>30 \mathrm{~Pa}\right)$ of samples did not show major inconsistencies with the predictions of this theoretical model. 


\section{Rectangular Hyperbola Model of Fist Normal Stress Difference of PNCs}

The following novel rectangular hyperbola model was successfully used to fit the PLA/NGP experimental $\mathrm{N}_{1}$ data of this study:

$$
N_{1}(\sigma, w)=\frac{P_{1} \sigma}{P_{2}+\sigma}
$$

Where, $P_{1}$ is the $\mathrm{N}_{1}$ asymptote, i.e. the value of $\mathrm{N}_{1}$ at infinite time when $\mathrm{N}_{1}$ plateaus, and $P_{2}$ is the stress asymptote, i.e. the value of stress at zero-first normal stress difference region $\left(N_{1}^{0}\right.$ at $10>\sigma>30 \mathrm{~Pa})$.

Table 3 displays the computed values of stress asymptotes $\left(\mathrm{P}_{1}\right.$ and $\left.\mathrm{P}_{2}\right)$ of the first normal stress differences of the samples. The difference between the maximum and minimum values of $\mathrm{N}_{1}$ asymptotes $\left(\mathrm{P}_{1}\right)$ is about 700 whereas it is minor for stress asymptotes $\left(\mathrm{P}_{2}\right)$. Consequently, it is evident that $\mathrm{P}_{1}$ is a function of mass fraction (w) whereas $\mathrm{P}_{2}$ is independent of $\square$ and it could signify the inherent characteristics of the polymeric matrix. Thus:

$$
N_{1}(\sigma, w)=\frac{P_{1}(w) \sigma}{P_{2}+\sigma}
$$

Figure 7 illustrates the fitting of the experimental results of $\mathrm{N}_{1}$ of PLA/NGP composites into the proposed rectangular hyperbola model (Eq. 20). The advantage of the proposed model of first normal stress difference to the existing power law models, i.e. Mall-Gleissle (Eq. 16) and Semenov (Eq. 13) models, of PNCs could be due to the inability of previous studies to measure the first normal stress difference at high shear stress region. Furthermore, the simulation of this model was successfully accomplished within several domains of stress via OriginPro 8 software. Figure 8 displays the simulation of $\mathrm{N}_{1}$ via application of the rectangular hyperbola model at different stress domains, i.e. $0.01<\sigma<1 \mathrm{~Pa}, 0.01<\sigma<500 \mathrm{~Pa}$ and 0.01 $<_{\sigma}<10^{4} \mathrm{~Pa}$, for neat PLA and PLA03. On one hand, it was apparent that the curves fit into power law model for $\sigma<1 \mathrm{~Pa}$ and could satisfy the previously proposed power law models. On the other hand, at higher stress domains $\left(10^{2}<\sigma<10^{4} \mathrm{~Pa}\right)$ both samples demonstrated 
power law behaviours at low stress region, while they ultimately asymptoted to constant magnitudes of $\mathrm{N}_{1}$ at high stress region through a rectangular hyperbola patterns.

\section{LCP}

Figure 9 demonstrates the experimental first normal stress difference values of both filled LCPs versus shear rate. The filled LCPs exhibited negative normal stress difference in the low shear rate region $\left(<10 \mathrm{~s}^{-1}\right)$. High shear rate results could not be obtained due to the slippage effect. It was observed that the first normal stress difference for LCP-A filled decreased up to the shear rate of $0.09 \mathrm{~s}^{-1}$. After this critical shear rate, although still negative, $\mathrm{N}_{1}$ started to increase. In the case of LCP-B filled, $\mathrm{N}_{1}$ initially decreased up to $0.12 \mathrm{~s}^{-1}$ and then started to increase. Filled LCP-A showed a significant decrease in $\mathrm{N}_{1}$ compared to filled LCP-B sample. Both filled LCPs showed anomalous negative first normal stress differences which is in accordance with previous studies [18].

It can be seen that both filled LCPs have glass fibres as the reinforcing material and the aspect ratio of their glass fibers is approximately 100 [73]. At low shear rates, the interaction between the fibers compensates the force attempting to align the fibers within the flow direction. Consequently, substantial resistances to deformation occurred at low shear rates. Moreover, fibre- fibre interactions compete with the elasticity of rigid rod-like molecules of LCPs at low shear rate region. Hence, these interactions could suppress the first normal stress difference and lead to negative values. Likewise, such anomalous behaviour of first normal stress difference has also been observed in concentrated suspensions where filler elements with high aspect ratio demonstrated competitiveness with elasticity at the low shear rate region and resulted in the occurrence of negative values of first normal stress difference [74]. Litchfield and Baird (2006) demonstrated that the suspension filled with long fibre (aspect ratio $>100$ ) showed unusual rheological behaviour and the value of first normal stress difference became negative at low shear rates [19].

Figure 10 shows the first normal stress difference results of unfilled LCP-A and B samples as a function of shear rate. It is clear from this figure that the magnitude of $\mathrm{N}_{1}$ increased as a 
function of shear rate in a positive mode. According to several studies, the magnitude of first normal stress difference may increase as a result of the incorporation of short fibres $[19,75$, 76]. However, the abnormal orientation of the existing rigid rod-like molecules in unfilled LCPs are responsible for the increase of the first normal stress differences. During the shear deformation, the rigid rod-like molecules of unfilled LCPs start to tumble [6] which could enhance the elasticity. Consequently, this could lead to the observed rise in the magnitude of the first normal stress difference of samples as depicted for unfilled LCPs (Fig. 10).

Figure 11 demonstrates the application of the proposed rectangular hyperbola model on unfilled LCP samples as a function of shear rate. The results exhibited a satisfactory agreement between the experimental data and the proposed model for unfilled samples in both low and high shear rate regions. As illustrated in Fig. 11, the precision and level of fitting of this model significantly improved as the magnitude of the shear rate increased. This could be attributable to the alignment of rod-like LCP molecules in the direction of flow at higher shear rate region and its subsequently lower rheological impact compared to the hydrodynamic effect of flow. The rigid rod-like molecules of LCPs possess anisotropic structure (different types of orientation) in the low shear rate region [9]. These rigid rod-like molecules exhibit different types of orientation, i.e. tumbling, wagging, kayaking, flowaligning or log-rolling. The variations of orientation occur with the increase of motion and at higher shear rates these molecules rotate to flow-aligning region [18]. Consequently, the molecules of LCPs shift their molecular phase from isotropic to anisotropic phase at increased shear deformation [10] and $\mathrm{N}_{1}$ data asymptote to a rate independent behaviour at high shear rates; leading to enhanced fits with the proposed rectangular hyperbola model.

LCPs exhibit pronounced shear thinning behaviour at low shear rate region, which leads a narrow range of available stresses for LCPs, thus, the variation of shear stress as a function of shear rate for this material is nominal and the stress does not vary significantly in response to the changes in shear rate. This could be also due to the effect of rod-like liquid crystals which align in the direction of flow at increased shear rates. Hence, the variation of shear stress with normal stress is small and the rectangular hyperbola model is not applicable to the $\mathrm{N}_{1}$-shear stress data. Filled LCPs exhibit substantial anomalous behaviour particularly on account of the morphology of the LCP molecules and the influence of glass fibres as previously explained. Therefore, their anomalous behaviour could not be described through utilizing simple rheological models. 


\section{Conclusion}

The findings of this study suggest that the anomalous behaviour of $\mathrm{N}_{1}$ could be due to the size, loading of fillers, imposed shear rate and the rigidity of the rod-like molecules, such as LCPs. $\mathrm{N}_{1}$ behaviour of PLA/NGP bionanocomposites was dependent on the level of loading of nanofillers as well as the shear rate beyond a critical value. To some extent this observation along with the existence of Newtonian behaviour of PLA/NGP composites at low shear rate could indicate the occurrence of the delamination of NGP nanofillers within PLA matrix. However, this study could not obtain a similar correlation between $\mathrm{N}_{1}$ and shear rate for liquid crystalline polymers in both high and low rate regions.

The predictability of $\mathrm{N}_{1}$ behaviours of PLA/NGP composites was examined through the Semenov power law model. This model could only predict the first normal stress difference behaviour in a limited shear stress spectrum within the power law region. Therefore, a rectangular hyperbola model was developed for the prediction of $\mathrm{N}_{1}$ as a function of shear stress. This novel model exhibited a satisfactory fit in both power law and plateau regions of neat PLA and PLA/NGP composites. The computational simulation outcomes of the model at different stress domains were also consistent with the experimental results of this study.

In the case of filled LCP, the long fibre-fibre interactions were competing with the elasticity of rigid rod like molecule at low shear rate region. Overall, these interactions suppressed the normal stress and led to negative values of $\mathrm{N}_{1}$. The rheological rectangular hyperbola model could not predict the negative normal stress difference of filled LCPs. However, in the case of unfilled LCPs, the $\mathrm{N}_{1}$ behaviour became positive since the orientation of those rigid rodlike molecules of unfilled LCPs enhanced the magnitude of $\mathrm{N}_{1}$. Regarding unfilled LCPs, satisfactory fittings were observed between the modelled values of $\mathrm{N}_{1}$ and the experimental data. 


\section{Table Captions}

Table 1. Compositions of PLA/NGP composites and their corresponding sample codes.

Table 2. Evaluation of Carreau-Yasuda and Semenov model parameters through computational fitting of the experimental data into Eqs. 18 and 13, respectively.

Table 3. Computed values of the model parameters of the proposed rectangular hyperbola model (Eq. 19) of neat PLA and PLA/NGP composites.

\section{Figure Captions}

Fig. 1. Illustration of steady shear rheological behaviour $\left(\mathrm{N}_{1}\right.$ and shear viscosity) of PLA02 versus shear rate at $\mathrm{T}=180{ }^{\circ} \mathrm{C}$.

Fig. 2. Steady shear viscosity of neat PLA and PLA-NGP composites at $\mathrm{T}=180{ }^{\circ} \mathrm{C}$.

Fig. 3. Illustration of first normal stress difference of neat PLA and PLA/NGP composites versus shear rate at $\mathrm{T}=180{ }^{\circ} \mathrm{C}$.

Fig. 4. Illustration of first normal stress difference of neat PLA and PLA/NGP composites versus shear stress at $\mathrm{T}=180{ }^{\circ} \mathrm{C}$. 
Fig. 5. The dependence of the first normal stress difference on the shear rate and filler concentration of the samples.

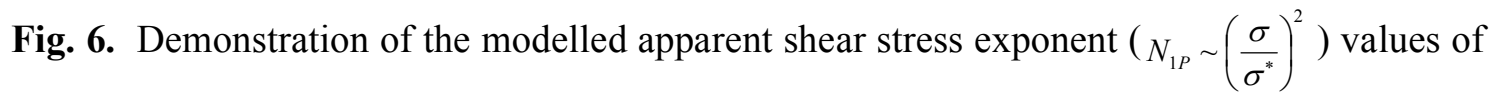
neat PLA and its composites via Semenov model (Eq.13).

Fig. 7. Fitting of experimental data of neat PLA and PLA/NGP composites into rectangular hyperbola model $\left(N_{1}(\sigma, w)=\frac{P_{1}(w) \sigma}{P_{2}+\sigma}\right)$ of first normal stress difference.

Fig. 8. Computational simulation results of the rectangular hyperbola model ( $\left.N_{1}(\sigma, w)=\frac{P_{1}(w) \sigma}{P_{2}+\sigma}\right)$ of $\mathrm{N}_{1}$ for (a) neat PLA and (b) PLA03.

Fig. 9. First normal stress difference as a function of shear rate at $350{ }^{\circ} \mathrm{C}$ for filled LCP-A and LCPB systems.

Fig. 10. First normal stress difference as a function of shear rate at $350{ }^{\circ} \mathrm{C}$ for unfilled LCP-A and LCP-B systems.

Fig. 11. Fitting of the experimental data of unfilled LCP-A and LCP-B into the rectangular hyperbola model $\left(N_{1}(\dot{\gamma}, w)=\frac{P_{1}(w) \dot{\gamma}}{P_{2}+\dot{\gamma}}\right)$ of first normal stress difference. 


\section{References}

1. C.W. Macosko, Rheology: Principles, Measurements, and Applications, Wiley-VCH, New York (1994).

2. M. Keentok, A.G. Georgescu, A.A. Sherwood, and R.I. Tanner, Journal of NonNewtonian Fluid Mechanics, 6, 3-4 (1980).

3. S. Ramachandran, H.W. Gao, and E.B. Christiansen, Macromolecules, 18, 4 (1985).

4. $\quad$ L.J. Kasehagen and C.W. Macosko, Journal of Rheology, 42, 6 (1998).

5. S. Chandrasekhar, Liquid Crystals, Cambridge University Press, Cambridge (1994).

6. G. Marrucci, Liquid Crystallinity in Polymers: Principles and Fundamental Properties, VCH Publishers, New York (1991).

7. W. Brostow, "An Introduction to Liquid Crystallinity” in Liquid Crystalline Polymers: From Structures to Applications, , Elsevier Applied Science, New York (1992).

8. C. Tai-S, Polymer Engineering and Science, 26, 13 (1986).

9. $\quad$ P.G. de Gennes and J. Prost, The Physics of Liquid Crystal, Clarendon Press, Oxford (1993).

10. S. Singh, Phase Transitions in Liquid Crystals, in Physics Reports 2000. p. 107-269.

11. M. Doi, Journal of Physical Science, 19, (1981).

12. S.G. Baek, J.J. Magda, and S. Cementwala, Journal of Rheology 37, (1993).

13. S.-G. Beak and J.J. Magda, Journal of Rheology, 37, 6 (1993).

14. G. Rienacker and S. Hess, Physica A, 267, (1999).

15. S.G. Baek, J.J. Magdaa, R.G. Larson, and H.D. Hudson, Journal of Rheology, 38, 5 (1994).

16. G. Kiss and R.S. Porter, Journal of Polymer Science, Polymer Symposia, 65, (1978).

17. C.-M. Huang, J.J. Magda, and R.G. Larson, Journal of Rheology, 43, (1999).

18. G. Marrucci and S. Guido, International Journal of Polymer Analysis and Characterization, 1, (1995).

19. D.W. Litchfield and D.G. Baird, Rheology Reviews, (2006).

20. M.R. Kamal and A. Mutel, Journal of Polymer Engineering, 5, 4 (1985).

21. Y.-G. Tao, W.K.d. Otter, and W.J. Briels, Macromolecules, 39, (2006).

22. A.V. Shenoy, Rheology of filled polymer systems, Kluwer Academic Publisher, London (1999).

23. J.M. Dealy and K.F. Wissburn, Melt Rheology and Its Roles in Plastics Processing, Chapman and Hall, New York (1990).

24. E. Narimissa, R. Gupta, M. Bhaskaran, and S. Sriram, Polymer Degradation and Stability, 97, 5 (2012).

25. E. Narimissa, R. Gupta, N. Kao, H.J. Choi, M. Jollands, and S.N. Bhattacharya, Polymer Engineering and Science, (2013).

26. E. Narimissa, R.K. Gupta, H.J. Choi, N. Kao, and M. Jollands, Polymer Composites, 33, 9 (2012).

27. A.S. Lodge and J. Meissner, Rheologica Acta, 11, 3-4 (1972).

28. J.M. Dealy and R.G. Larson, Structure and Rheology of Molten Polymers: From Structure to Flow Behaviour and Back Again, Hnaser, Munich (2006).

29. H.M. Laun, Rheologica Acta, 17, 1 (1978).

30. K. Osaki, N. Bessho, T. Kojimoto, and M. Kurata, Journal of Rheology, 23, 5 (1979).

31. C.M. Vrentas and W.W. Graessley, Journal of Non-Newtonian Fluid Mechanics, 9, 34 (1981).

32. V. Pryamitsyn and V. Ganesan, Journal of Rheology, 50, 5 (2006). 
33. M. Doi and S.F. Edwards, The Theory of Polymer Dynamics, Oxford University Press, Oxford (1986).

34. A.N. Semenov, A.V. Subbotin, G. Hadziioannou, G. Ten Brinke, E. Manias, and M. Doi, Macromolecular Symposia, 121, (1997).

35. A. Subbotin, A. Semenov, E. Manias, G. Hadziioannou, and G. Ten Brinke, Macromolecules, 28, 11 (1995).

36. G.K. Batchelor, An Introduction to Fluid Dynamics, Cambridge University Press, Cambridge (1967).

37. J.F. Brady, The Journal of Chemical Physics, 99, 1 (1993).

38. J.F. Brady and J.F. Morris, Journal of Fluid Mechanics, 348, (1997).

39. R.A. Lionberger and W.B. Russel, Journal of Rheology, 41, 2 (1997).

40. J. Bicerano, J.F. Douglas, and D.A. Brune, Journal of Macromolecular Science Reviews in Macromolecular Chemistry and Physics, 39 C, 4 (1999).

41. R.G. Larson, The Structure and Rheology of Complex Fluids, (1999).

42. K.J. Kim and J.L. White, Polymer Engineering and Science, 39, 11 (1999).

43. J.F. Le Meins, P. Moldenaers, and J. Mewis, Industrial and Engineering Chemistry Research, 41, 25 (2002).

44. L.L. Li and J.L. White, Rubber Chemistry and Technology, 69, 4 (1996).

45. A.B. Metzner, Journal of Rheology, 29, 6 (1985).

46. Y. Wang and J.J. Wang, Polymer Engineering and Science, 39, 1 (1999).

47. T. Kataoka, T. Kitano, M. Sasahara, and K. Nishijima, Rheologica Acta, 17, 2 (1978).

48. N. Ohl and W. Gleissle, Journal of Rheology, 37, 2 (1993).

49. M.A. Osman, A. Atallah, T. Schweizer, and H.C. Öttinger, Journal of Rheology, 48, 5 (2004).

50. S.E. Mall-Gleissle, W. Gleissle, G.H. McKinley, and H. Buggisch, Rheologica Acta, 41, 1 (2002).

51. B.K. Aral and D.M. Kalyon, Journal of Rheology, 41, 3 (1997).

52. R. Krishnamoorti, J. Ren, and A.S. Silva, Journal of Chemical Physics, 114, 11 (2001).

53. J.L. White and H. Tanaka, Journal of Applied Polymer Science, 26, 2 (1981).

54. N. Othman, B. Jazrawi, P. Mehrkhodavandi, and S.G. Hatzikiriakos, Rheologica Acta, 51, 4 (2012).

55. J.D.F. Ramsay, Journal of Colloid and Interface Science, 109, 2 (1986).

56. S. Sinha Ray, Journal of Industrial and Engineering Chemistry, 12, 6 (2006).

57. V. Pryamitsyn and V. Ganesan, Macromolecules, 39, 2 (2006).

58. F. Brochard and P.G. De Gennes, Langmuir, 8, 12 (1992).

59. D.J. Henson and M.E. Mackay, Journal of Rheology, 39, 2 (1995).

60. Y. Inn and S.Q. Wang, Physical Review Letters, 76, 3 (1996).

61. K.B. Migler, H. Hervet, and L. Leger, Physical Review Letters, 70, 3 (1993).

62. H.J. Choi, S.J. Vinay Iii, and M.S. Jhon, Polymer, 40, 10 (1999).

63. S.N. Bhattacharya, R.K. Gupta, and M.R. Kamal, Polymeric Nanocomposites: Theory and Practice, Hanser Gardner Pubns, Munich (2007).

64. J.L. White, L. Czarnecki, and H. Tanaka, Rubber Chemistry and Technology, 53, 4 (1980).

65. S.A. Khan and R.K. Prud'Homme, Reviews in Chemical Engineering, 4, 3-4 (1987).

66. C. Dae Han, Journal of Applied Polymer Science, 18, 3 (1974).

67. H. Tanaka and J.L. White, Polymer Engineering and Science, 20, 14 (1980).

68. J. Ren and R. Krishnamoorti, Macromolecules, 36, 12 (2003).

69. R. Prasad, R.K. Gupta, F. Cser, and S.N. Bhattacharya, Journal of Polymer Engineering, 25, 4 (2005). 
70. Y. Wang, J. Xu, S.E. Bechtel, and K.W. Koelling, Rheologica Acta, 45, 6 (2006).

71. E.P. Giannelis, R. Krishnamoorti, and E. Manias, Advances in Polymer Science, 138, (1999).

72. P.J. Carreau, D.C.R. De Kee, and R.P. Chhabra, Rheology of Polymeric Systems, Carl Hanser Verlag GmbH \& Co New York (1997).

73. A. Rahman, R.K. Gupta, B. S.N., S. Ray, and F. Costa, International Polymer Processing, (2012).

74. E.M. Susanne, W. Gleissle, G.H. McKinley, and H. Buggisch, Rheol Acta, 41, (2002).

75. S.A.A. Ramazani, A. Ait-Kadi, and M. Grmela, Journal of Rheology, 45, 4 (2001).

76. P.R.A. Eberle, D.G. Baird, and P. Wapperom, Industrial and Engineering Chemistry Research 47, (2008). 
Table 1. Compositions of PLA/NGP composites and their corresponding sample codes.

\section{Sample Code}

\begin{tabular}{cccccc}
\cline { 2 - 5 } Sample Compositions & neat PLA & PLA01 & PLA02 & PLA03 & PLA05 \\
\hline PLA content (wt\%) & 100 & 99 & 98 & 97 & 95 \\
NGP content (wt\%) & 0 & 1 & 2 & 3 & 5
\end{tabular}


Table 2. Evaluation of Carreau-Yasuda and Semenov model parameters through computational fitting of the experimental data into Eqs. 18 and 13, respectively.

\begin{tabular}{|c|c|c|c|c|c|c|c|c|}
\hline \multirow[b]{2}{*}{ Sample } & \multicolumn{5}{|c|}{ Carreau-Yasuda Model } & \multicolumn{3}{|c|}{ Semenov Model } \\
\hline & $\eta_{0}$ (Pa.s) & $\tau(\mathrm{s})$ & $\mathbf{a}\left(\mathrm{s}^{-1}\right)$ & $\mathbf{n}$ & $\mathbf{r}^{2}$ & $\ddot{\theta}^{*}\left(\mathrm{~s}^{-1}\right)$ & $\begin{array}{c}\eta_{P}^{0} \\
(\text { Pa.s) }\end{array}$ & $\sigma^{*}(\mathrm{~Pa})$ \\
\hline neat PLA & $1.26 \mathrm{E}+03$ & 0.06 & 2.18 & -22.0 & 0.94 & 2.2 & $1.26 \mathrm{E}+03$ & $2.75 \mathrm{E}+03$ \\
\hline PLA01 & $1.44 \mathrm{E}+03$ & 0.14 & 1.46 & -3.8 & 0.94 & 1.5 & $1.44 \mathrm{E}+03$ & $2.11 \mathrm{E}+03$ \\
\hline PLA02 & $1.65 \mathrm{E}+03$ & 0.07 & 1.18 & -5.0 & 0.92 & 1.2 & $1.65 \mathrm{E}+03$ & $1.94 \mathrm{E}+03$ \\
\hline PLA03 & $1.81 \mathrm{E}+03$ & 0.18 & 1.66 & -2.8 & 0.96 & 1.7 & $1.81 \mathrm{E}+03$ & $2.99 \mathrm{E}+03$ \\
\hline PLA05 & $1.99 \mathrm{E}+03$ & 0.18 & 1.30 & -2.8 & 0.96 & 1.3 & $1.99 \mathrm{E}+03$ & $2.58 \mathrm{E}+03$ \\
\hline
\end{tabular}


Table 3. Computed values of the model parameters of our proposed rectangular hyperbola model (Eq. 19) of neat PLA and PLA/NGP composites.

\begin{tabular}{c|c|c|c} 
Sample & $\mathbf{P}_{\mathbf{1}}$ & $\mathbf{P}_{\mathbf{2}}$ & $\mathbf{R}^{\mathbf{2}}$ \\
\hline neat PLA & $1.81 \mathrm{E}+3$ & 76 & 0.98 \\
PLA01 & $1.32 \mathrm{E}+3$ & 53 & 0.95 \\
PLA02 & $1.77 \mathrm{E}+3$ & 52 & 0.94 \\
PLA03 & $1.10 \mathrm{E}+3$ & 123 & 0.96 \\
PLA05 & $1.34 \mathrm{E}+3$ & 119 & 0.99
\end{tabular}




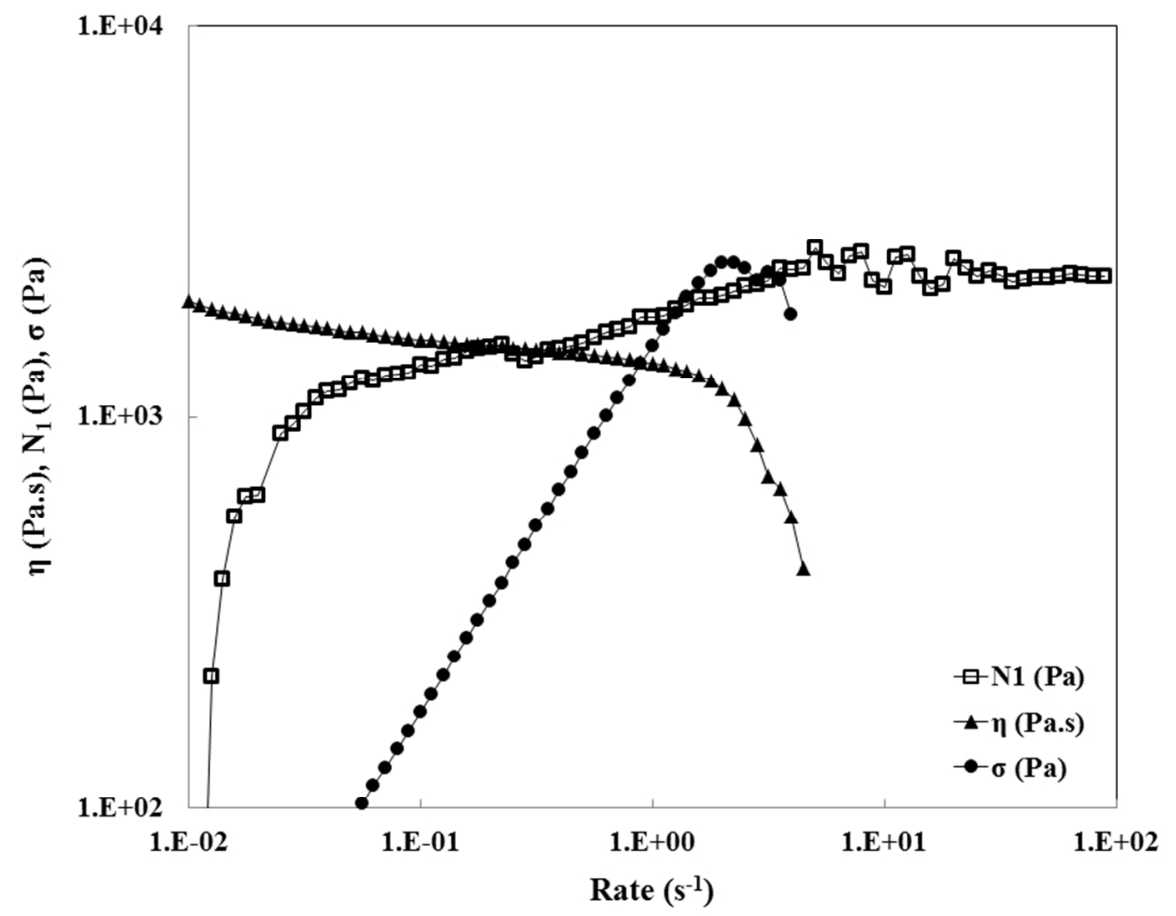

Fig. 1. Illustration of steady shear rheological behaviour ( $\mathrm{N} 1$ and shear viscosity) of PLA02 versus shear rate at $\mathrm{T}=180^{\circ} \mathrm{C}$. 


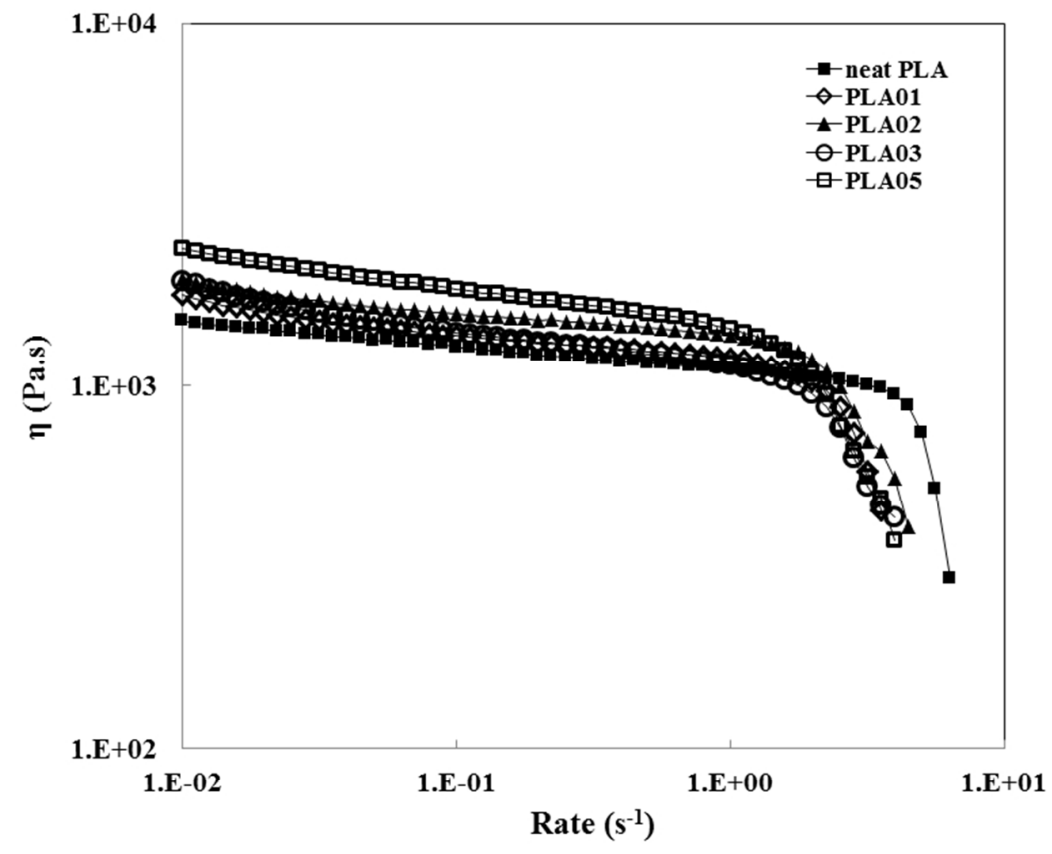

Fig. 2. Steady shear viscosity of neat PLA and PLA-NGP composites at $\mathrm{T}=180^{\circ} \mathrm{C}$. 


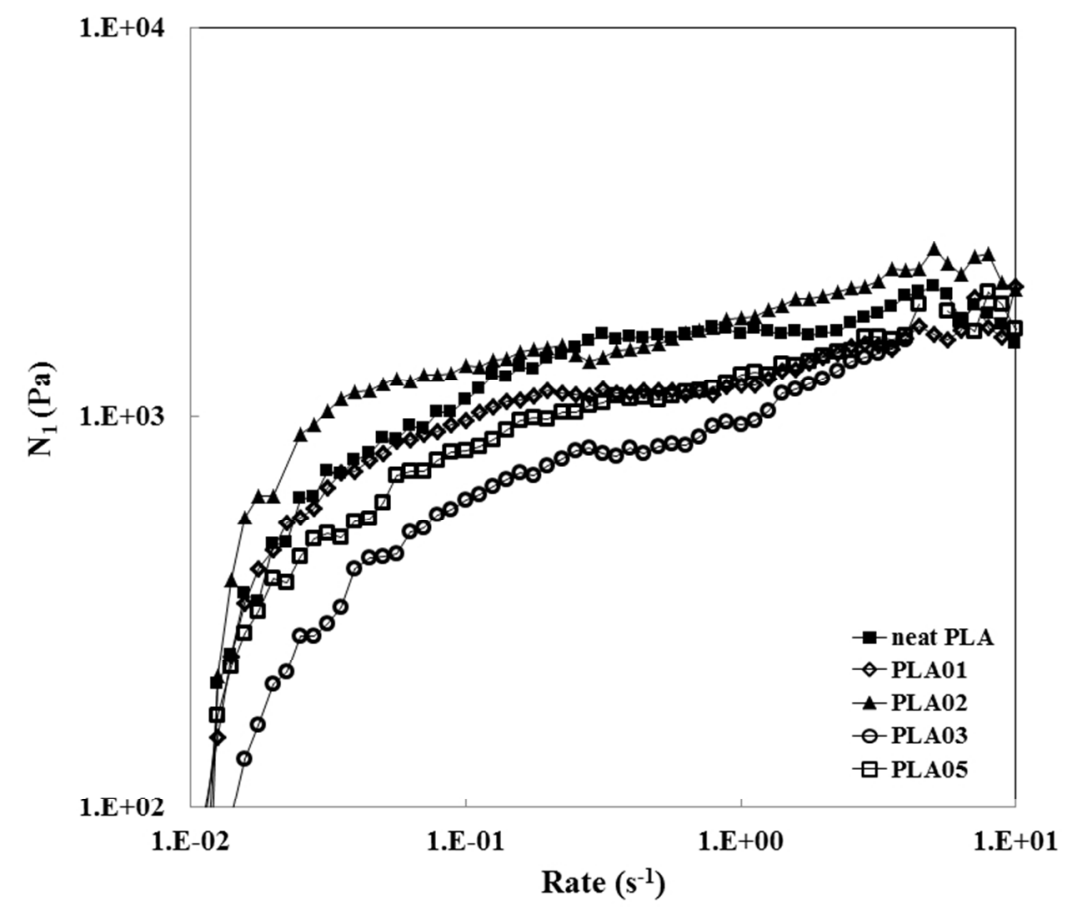

Fig. 3. Illustration of first normal stress difference of neat PLA and PLA/NGP composites versus shear rate at $\mathrm{T}=180^{\circ} \mathrm{C}$. 


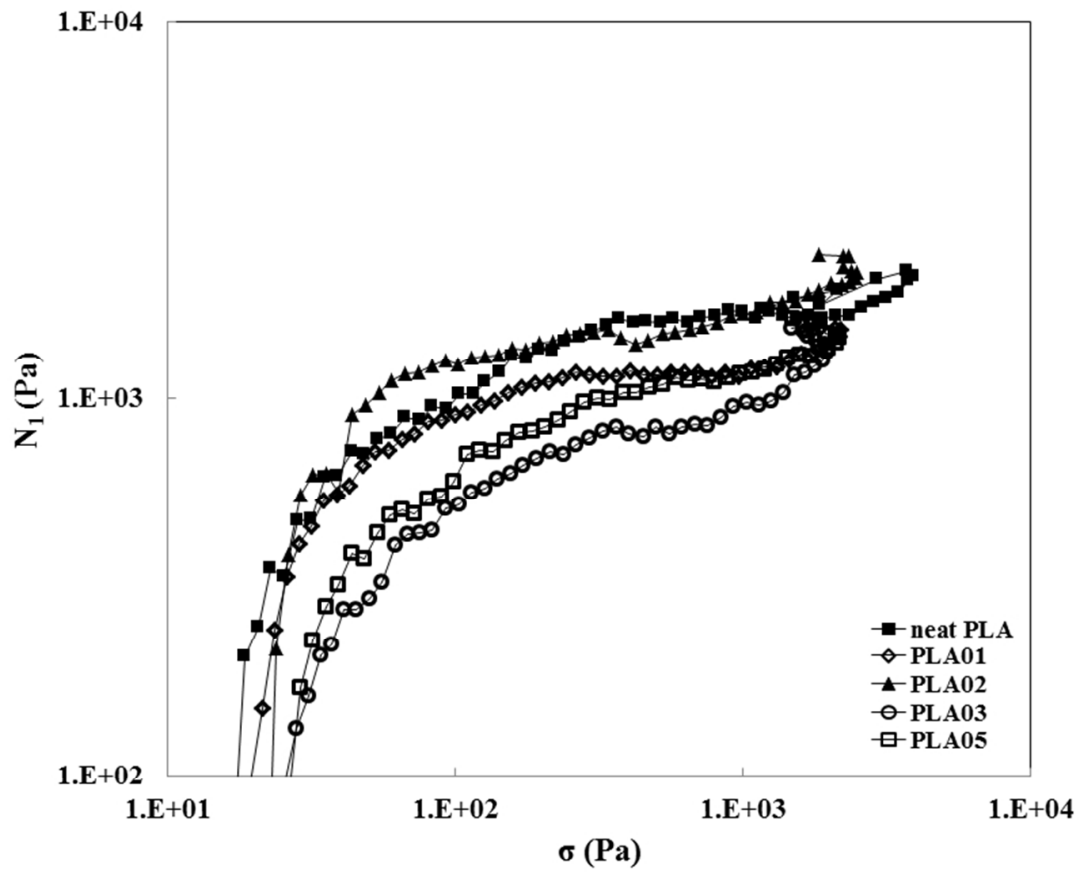

Fig. 4. Illustration of first normal stress difference of neat PLA and PLA/NGP composites versus shear stress at $\mathrm{T}=180^{\circ} \mathrm{C}$. 


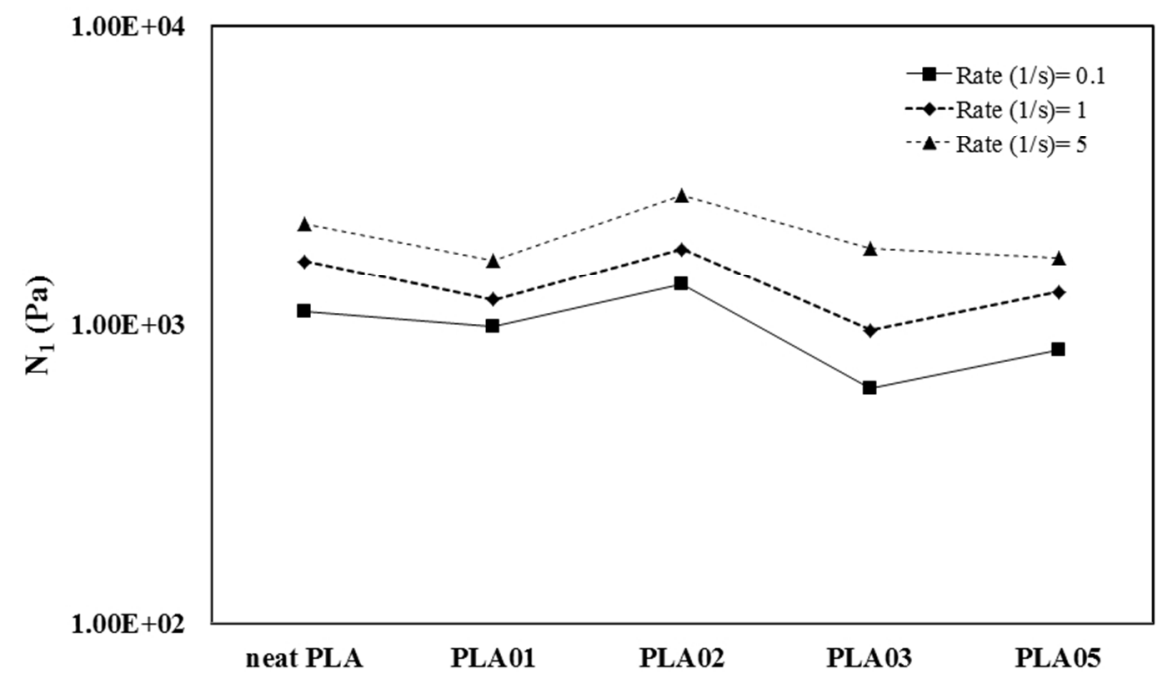

Fig. 5. The dependence of the first normal stress difference on the shear rate and filler concentration of the samples. 


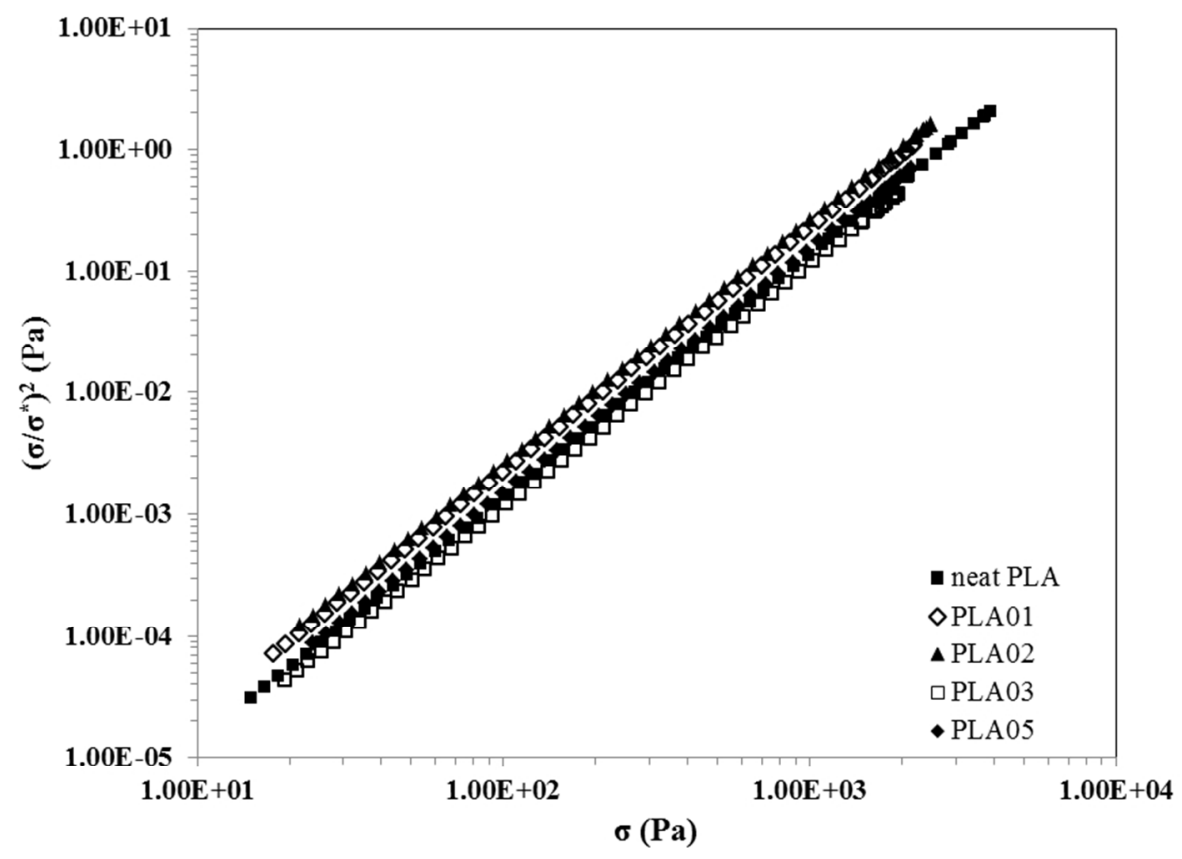

Fig. 6. Demonstration of the modelled apparent shear stress exponent ( ) values of neat PLA and its composites via Semenov model (Eq.13). 

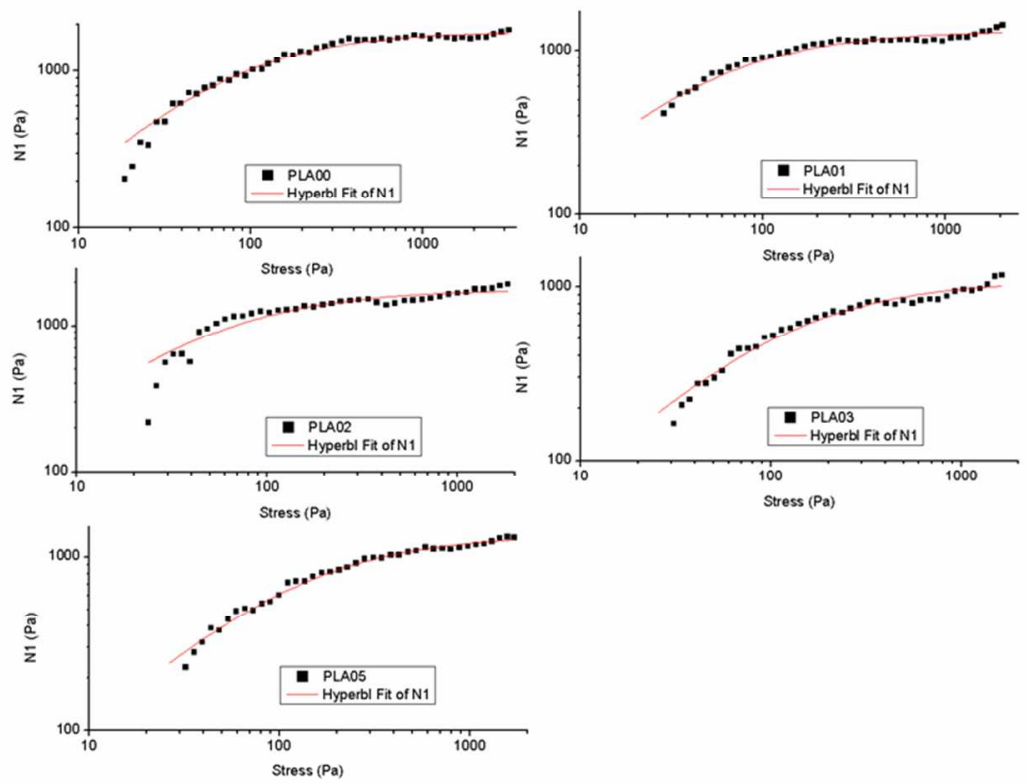

Fig. 7. Fitting of experimental data of neat PLA and PLA/NGP composites into rectangular hyperbola model ( ) of first normal stress difference. 


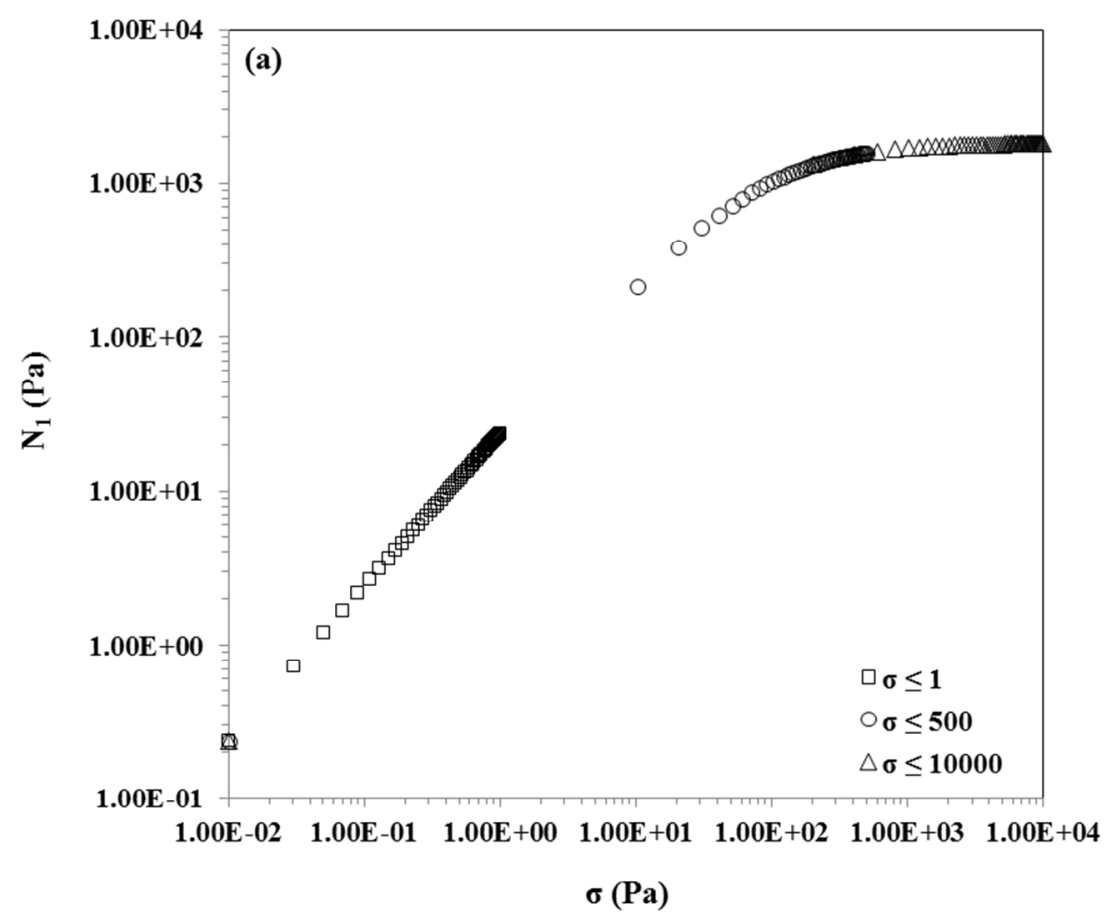

Fig. 8. Computational simulation results of the rectangular hyperbola model ( ) of N1 for (a) neat PLA and (b) PLA03. 


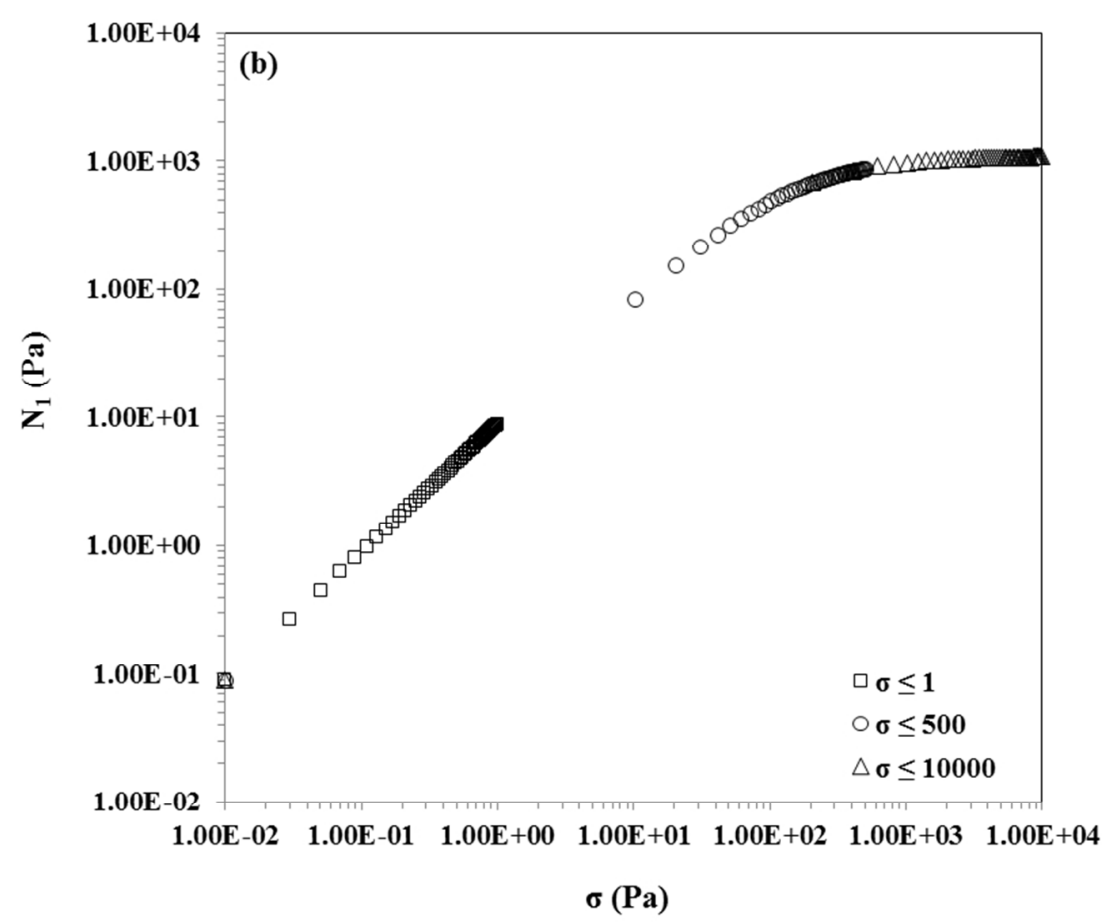

Fig. 8. Computational simulation results of the rectangular hyperbola model ( ) of N1 for (a) neat PLA and (b) PLA03. 


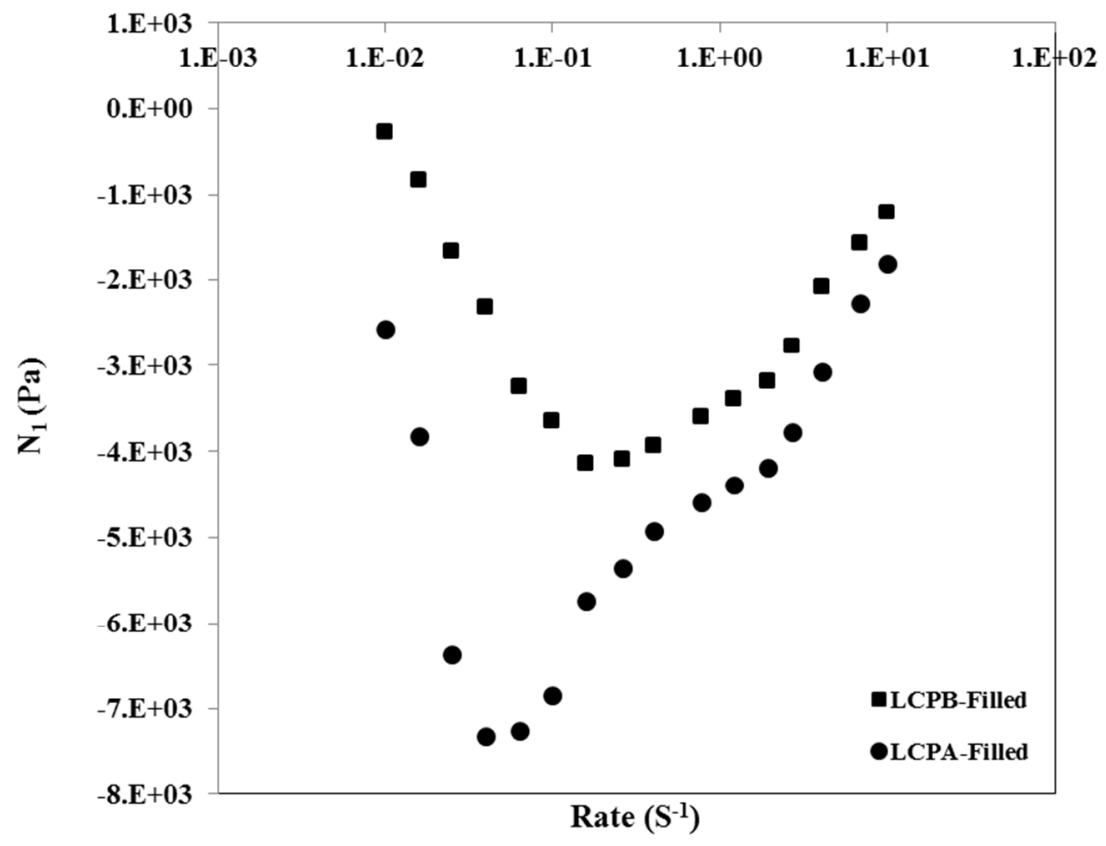

Fig. 9. First normal stress difference as a function of shear rate at $350^{\circ} \mathrm{C}$ for filled LCP-A and LCPB systems. 


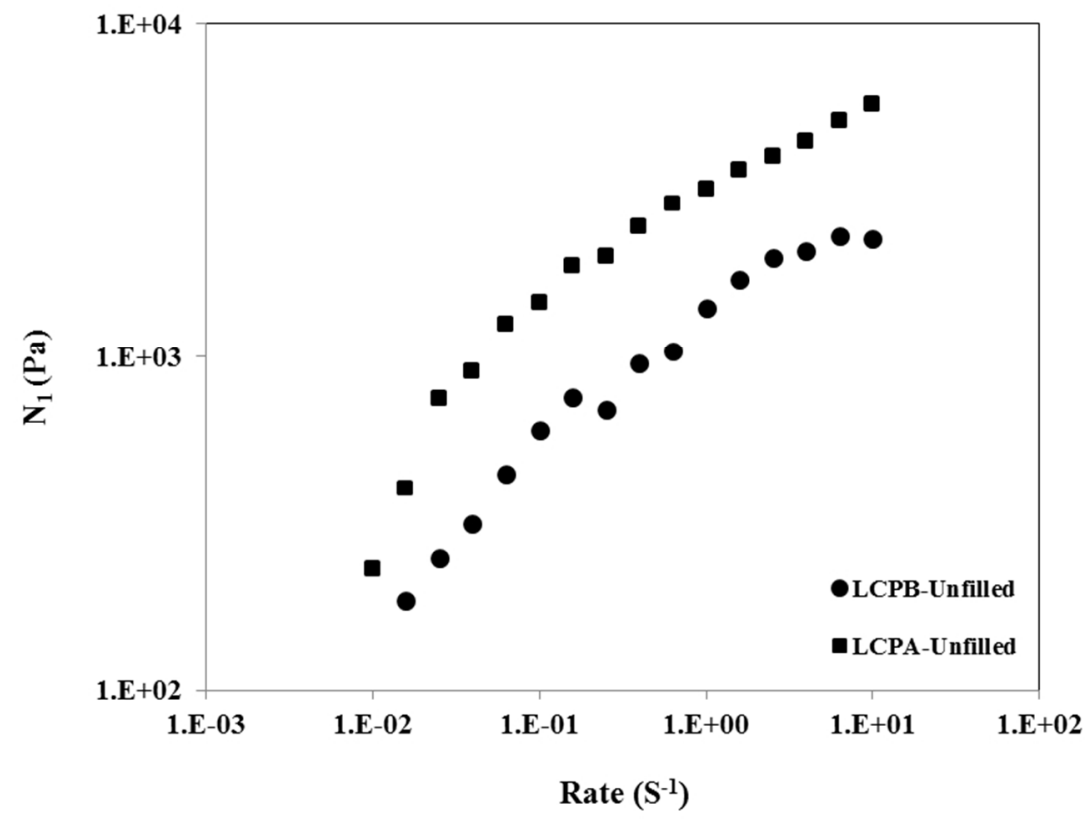

Fig. 10. First normal stress difference as a function of shear rate at $350^{\circ} \mathrm{C}$ for unfilled LCP-A and LCP-B systems. 

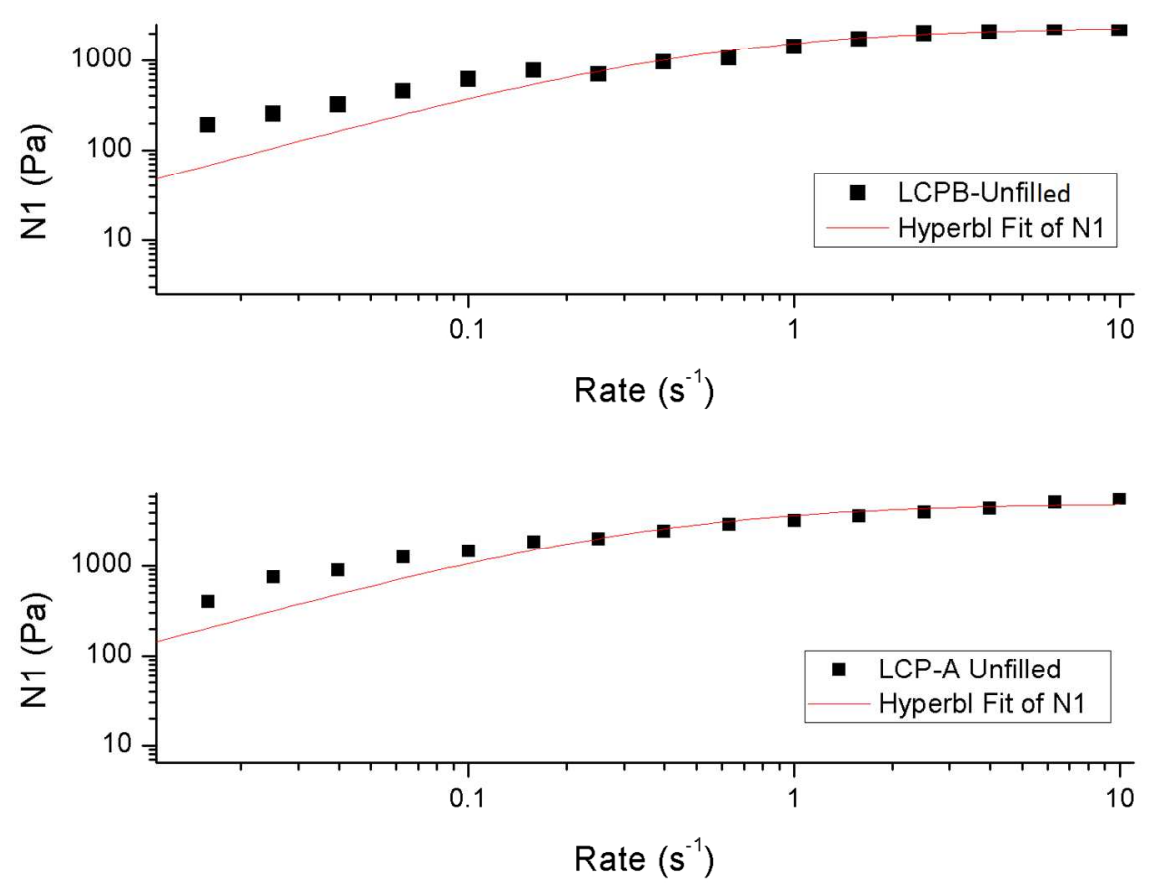

Fig. 11. Fitting of experimental data of unfilled LCP-A and LCP-B into rectangular hyperbola model ( ) of first normal stress difference. 